\title{
Pathology of Candida infection in oral HIV-associated Kaposi sarcoma: a descriptive study.
}

SADJ June 2018, Vol 73 no 5 p354 - p358

S Meer ${ }^{1}$, A Sibda $^{2}$

\begin{abstract}
Aims and objectives: To determine the frequency and histomorphology of secondary Candida infection in oral HIV-associated Kaposi sarcoma (HIV-KS) and to describe the demographics of patients with oral HIV-KS with and without secondary Candida infection.
\end{abstract}

Materials and methods: Haematoxylin and eosin, and periodic acid-Schiff stains of 32 oral HIV- KS were examined histologically for intensity and morphology of Candida colonisation, depth of invasion, number of organisms, epithelial reactions and inflammatory response. Depth of Candida invasion and severity of infection were correlated with CD4 T-cell counts of HIV-positive patients.

Results: Forty-one percent of oral HIV-KS were secondarily infected with Candida $(n=13)$. Intensity varied from an isolated single pseudohyphus to matted colonies. Whilst in most cases, organisms did not invade beyond the parakeratin layer, pseudohyphae extended into stratum spinosum in two cases, and a single case showed a pseudohyphus within the lamina propria. Two cases showed pseudohyphae in the pyogenic membrane. Neutrophilic permeation of epithelium, commonly associated with Candida infection was frequently present even in absence of Candida infection.

Conclusion: Oral HIV-KS is commonly secondarily infected with large numbers of Candida organisms. Morphological characteristics of secondary Candida infection in surface epithelium of HIV-KS suggest an altered pathogenetic pathway. Further studies are indicated.

1. Shabnum Meer: BChD (UWC), MDent Wits), FCPath (SA), Associate Professor, Head Clinical Unit, Department of Oral Pathology, Faculty of Health Sciences, University of the Witwatersrand, Johannesburg, South Africa.

2. Arshaad Sibda: BDS, MSC Dent (Wits). Research student, Department of Oral Pathology, Faculty of Health Sciences, University of the Witwatersrand, Johannesburg, South Africa.

\section{Corresponding author}

\section{Shabnum Meer:}

Associate Professor, Department of Oral Pathology, Faculty of Health Sciences, Private Bag 3, University of the Witwatersrand, Johannesburg, South Africa, 2050. Tel: +27 (0)11 717 2523. Fax: +27 (0)11 7172146.

E-mail: shabnum.meer@wits.ac.za. or shabnum.meer@nhls.ac.za

\section{INTRODUCTION}

The surface epithelium in oral human immunodeficiency virus-associated Kaposi sarcoma (HIV-KS) frequently shows secondary Candida infection with varying degrees of tissue invasion. The pathogenesis of such opportunistic fungal infections probably differs in oral HIV-KS, other HIVrelated oral disease, and infection of normal oral mucosa in HIV-positive patients. ${ }^{1}$ Differences in pathogenetic pathways may vary in histomorphology, frequency or intensity of infection. The aim was to determine the frequency and histomorphology of secondary Candida infection of surface epithelium in oral HIV-KS, and to highlight patient demographics in oral HIV-KS with and without secondary Candida infection of overlying epithelium.

\section{MATERIALS AND METHODS}

Thirty-two oral HIV-KS diagnosed in the Department of Oral Pathology, University of the Witwatersrand, South

\section{Table 1: Criteria for which Oral HIV-KS were histologically examined}

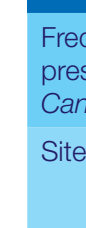

Frequency and presence of secondary andida infection

Site of infection

\footnotetext{
De
}

\begin{tabular}{|c|c|}
\hline & $\begin{array}{l}\text { - epithelium and connective tissue } \\
\text { - pyogenic membrane only }\end{array}$ \\
\hline $\begin{array}{l}\text { Foci and intensity of } \\
\text { Candida infection }\end{array}$ & $\begin{array}{l}\text { - mild, moderate or severe } \\
\text { - number of pseudohyphae and } \\
\text { yeasts }\end{array}$ \\
\hline $\begin{array}{l}\text { Depth of Candida } \\
\text { penetration }\end{array}$ & $\begin{array}{l}\text { - } \quad \text { superficial parakeratin only } \\
\text { spinous layer } \\
\text { - parakeratin, deep spinous layer } \\
\text { and lamina propria } \\
\text { - pyogenic membrane in ulcerated } \\
\text { areas }\end{array}$ \\
\hline $\begin{array}{l}\text { Presence of Candida } \\
\text { organisms }\end{array}$ & $\begin{array}{l}\text { - pseudohyphae only } \\
\text { - pseudohyphae with yeasts } \\
\text { micro-abscesses }\end{array}$ \\
\hline \multicolumn{2}{|c|}{ Presence of epithelial hyperplasia } \\
\hline \multicolumn{2}{|c|}{ Presence and type of inflammatory cells in lamina propria } \\
\hline $\begin{array}{l}\text { Correlation of preser } \\
\text { Candida infection wi }\end{array}$ & $\begin{array}{l}\text { ensity and depth of invasion } \\
\text { counts at time of biopsy }\end{array}$ \\
\hline
\end{tabular}




\begin{tabular}{|c|c|c|c|c|c|c|c|}
\hline & & \multicolumn{2}{|c|}{$\begin{array}{l}\text { HIV-KS } \\
n=32\end{array}$} & \multicolumn{2}{|c|}{$\begin{array}{c}\text { HIV-KS } 2^{\circ} \text { Candida }+ \\
n=13\end{array}$} & \multicolumn{2}{|c|}{$\begin{array}{c}\text { HIV-KS } 2^{\circ} \text { Candida - } \\
n=19\end{array}$} \\
\hline & & M & $F$ & M & $F$ & M & $F$ \\
\hline \multirow[t]{5}{*}{ Age and Gender } & Mean & 45.5 & 41.5 & 45.5 & 42 & 49.5 & 40.5 \\
\hline & Mean (total) & \multicolumn{2}{|c|}{41.5} & \multicolumn{2}{|c|}{42} & \multicolumn{2}{|c|}{41.5} \\
\hline & Median (total) & \multicolumn{2}{|c|}{41.5} & \multicolumn{2}{|c|}{42} & \multicolumn{2}{|c|}{41.5} \\
\hline & Total & 12 (37.5\%) & $20(62.5 \%)$ & $6(46.15 \%)$ & 7 (53.84\%) & $6(31.57 \%)$ & 13 (68.42\%) \\
\hline & M:F ratio & \multicolumn{2}{|c|}{$1: 1.7$} & \multicolumn{2}{|c|}{$1: 1.2$} & \multicolumn{2}{|c|}{$1: 2.2$} \\
\hline \multirow[t]{8}{*}{ Site } & Palate & 5 & 7 & 3 & 1 & 2 & 6 \\
\hline & Tongue & 4 & 6 & 2 & 4 & 2 & 2 \\
\hline & Gingiva & 1 & 2 & 0 & 1 & 1 & 1 \\
\hline & Labial mucosa & 0 & 1 & 0 & 0 & 0 & 1 \\
\hline & Floor of mouth & 0 & 1 & 0 & 1 & 0 & 0 \\
\hline & Retromolar area & 0 & 1 & 0 & 0 & 0 & 1 \\
\hline & Buccal mucosa & 1 & 0 & 0 & 0 & 1 & 0 \\
\hline & $>1$ site & 1 & 2 & 0 & 1 & 1 & 1 \\
\hline Inflammation: intensity & & & & $n$ & $\%$ & & \\
\hline \multirow[t]{3}{*}{ Acute } & Mild & & & 11 & 22.9 & & \\
\hline & Moderate & & & 6 & 12.5 & & \\
\hline & Severe & & & 1 & 2.1 & & \\
\hline \multirow[t]{3}{*}{ Chronic } & Mild & & & 9 & 18.8 & & \\
\hline & Moderate & & & 0 & 0 & & \\
\hline & Severe & & & 0 & 0 & & \\
\hline \multirow[t]{3}{*}{ Acute and chronic } & Mild & & & 11 & 22.9 & & \\
\hline & Moderate & & & 2 & 4.2 & & \\
\hline & Severe & & & 0 & 0 & & \\
\hline No inflammation & & & & 8 & 16.7 & & \\
\hline
\end{tabular}

Africa over a five-year period were analysed. Data included patient age, gender, site of lesion, HIV status and CD4 counts. Ethics clearance was granted by the Human Research Ethics Committee (Medical), University of the Witwatersrand, Johannesburg (M00/08/29; M08.03.25).

Haematoxylin and eosin (H\&E) and periodic acid Schiff (PAS) stained $4 \mu$ sections of HIV-seropositive oral KS (HIV-KS) were histologically examined for the criteria listed in Table 1. This is primarily a descriptive histomorphologic study with data being of a descriptive nature without statistical comparison.

\section{RESULTS}

The 32 patients who presented with oral HIV-KS ranged in age from 20 to 63 years and were mainly in the fourth decade ( $M: F=1: 1.7)$. The age of males was not statistically different from females ( $p>0.5)$. The site most affected was the palate (37.5\%) followed by the tongue (31.5\%) (Table 2).

Only $40.6 \%$ of oral HIV-KS showed secondary Candida infection with PAS positive pseudohyphae and yeast cells in the surface epithelium or pyogenic membrane. The remaining 59.4\% showed no Candida infection. The age of patients with oral HIV-KS secondarily infected with Candida ranged from 21-63 years; with most cases in the fourth and third decades (M:F=1:1.2). The site most affected was the tongue (46.2\%) followed by the palate (30.8\%) (Table 2). The age range of the $19 \mathrm{HIV}$-positive patients with oral HIVKS not secondarily infected with Candida was 20-63 years. Most cases occurred in the fourth decade, followed by the third, fifth and seventh decades in both males and females, with a M:F ratio of 1:2.2. The most common site was the palate (42.1\%) followed by the tongue (10.5\%) (Table 2).

Of the 13 oral HIV-KS positive for Candida, pseudohyphae penetrated the parakeratin layer only (46.2\%) (Figures $1 a, b, c)$, both the pyogenic membrane and parakeratin layer simultaneously (7.7\%), the superficial epithelium (7.7\%) and deep stratum spinosum (15.4\%) (Figures 2a,b). In $15.4 \%$ of cases, Candida pseudohyphae were noted in the necrotic slough only (Figure 1d). There was a single exceptional case of severe Candida colonisation with pseudohyphae penetrating the lamina propria and HIV-KS tissue (Figure 2c).

Secondary Candida infection ranged from severe (46.2\%) to moderate (23.1\%) to mild (30.8\%) (Figures 1c,d). Mild infection showed penetration into tissues by only single, isolated Candida organisms, usually in the superficial parakeratin layer (Figure 1e). Moderately infected cases showed greater numbers of Candida pseudohyphae and yeasts. The parakeratin layer was thicker, with desquamation, and organisms mainly in the desquamated keratin and superficial parakeratin layers (Figures 1b,c). 

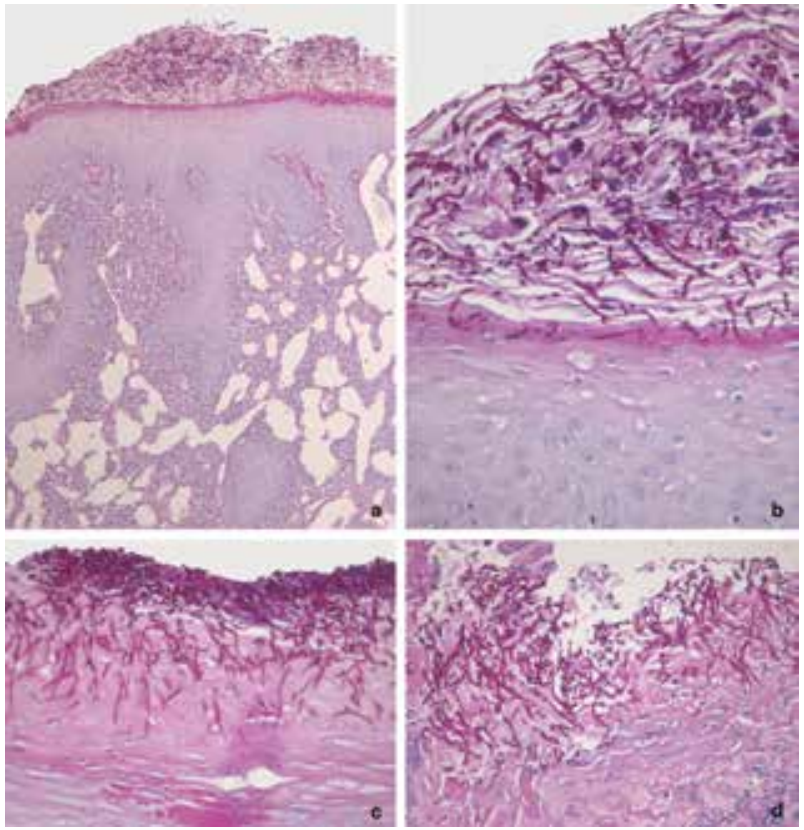

Figure 1: (a) Oral HIV-KS: parakeratin overlying epithelium showing pseudoepitheliomatous hyperplasia and heavy infiltration by Candida pseudohyphae (PAS; x10) (b). Despite heavy colonisation by Candida yeasts and pseudohyphae at the junction of parakeratin and stratum spinosum, penetration beyond parakeratin does not usually occur (PAS, x40) (c). Severe surface Candida infection by yeasts and pseudohyphae, with the latter showing a higher penetrative capacity (PAS, $x 40)$ (d). This is an unusual finding of Candida organisms growing in the pyogenic membrane (PAS, x20).

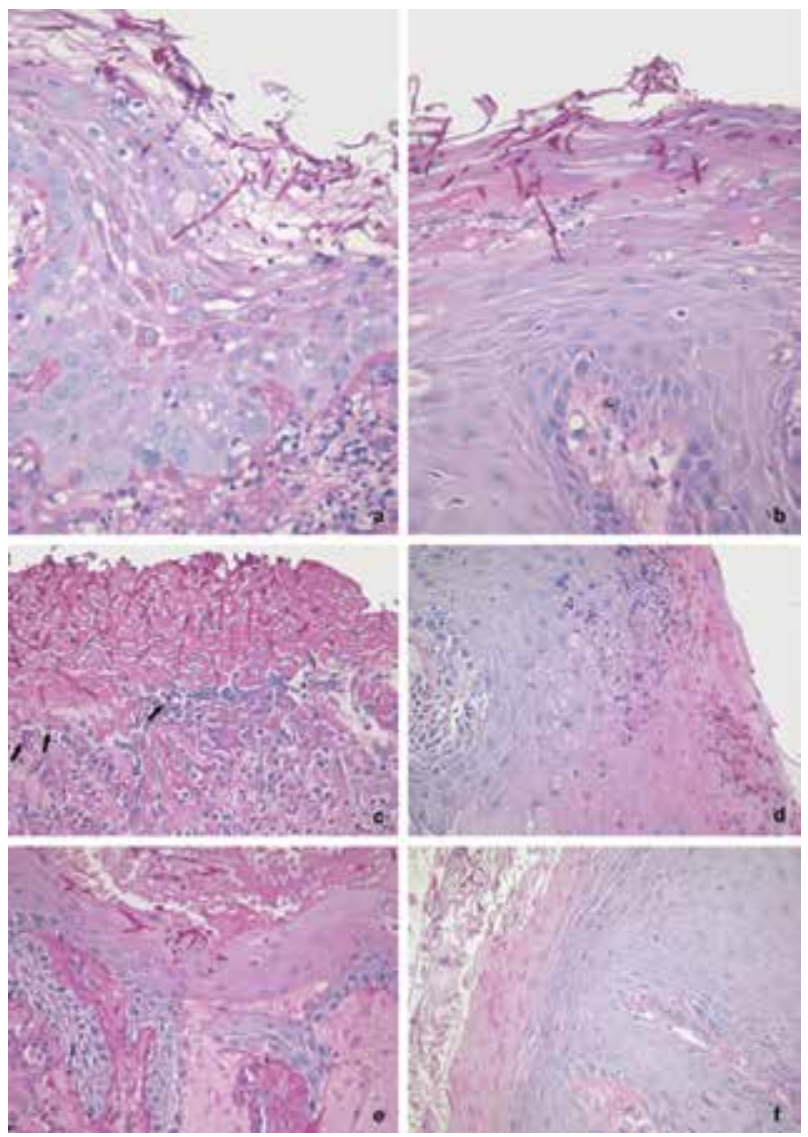

Figure 2: $(a, b)$ Candida infiltration restricted to parakeratin with only single pseudohyphus penetrating the spinous cell layer, and chronic inflammation in the lamina propria underlying the Candida invasion (PAS, x40). (c) Deep penetration by Candida into ulcerated oral HIV-KS, connective tissue and lesional tissue (arrowed); intense inflammation in the lamina propria (PAS, x40). (d) Candida restricted to parakeratin with neutrophilic micro-abscesses (PAS, $\mathrm{x} 40)$. (e, f) Candida in parakeratin without inflammation in the epithelium or connective tissue (PAS, $x 40$ ).
Severe infection showed matted colonies of Candida pseudohyphae and yeasts in both the desquamated keratin and parakeratin layers (Figure 1c), sometimes reaching the stratum spinosum (Figures $2 a, b)$. The yeasts always remained on the surface.

Neutrophilic micro-abscesses in superficial parakeratin were present in $53.8 \%$ of cases, however no Candida organisms were seen in close association to the microabscesses in $46.2 \%$ of cases. Surprisingly, Candida pseudohyphae were present without micro-abscesses in $53.8 \%$ of cases (Figures 2d,e,f).

Inflammation beneath Candida infected areas in the lamina propria ranged from severe $(7.7 \%)$ to moderate (23.1\%) to mild (53.8\%), with areas having no inflammation (15.4\%) (Figure 2). Epithelial hyperplasia (Figure 1a) was noted in $61.5 \%$ of infected cases, usually with severe infection. Candida positive cases were characterised by hyperparakeratosis and hyperplasia of surface epithelium compared to non-infected cases. Pseudoepitheliomatous hyperplasia was present in $7.7 \%$ of cases with severe infection.

An inverse relationship was noted between the CD4 count in the 13 oral HIV-KS secondarily infected with Candida and the presence, intensity and depth of penetration of Candida infection (Table 3). Cases with low CD4 counts showed deeper penetration of Candida pseudohyphae (Table 3). The 19 oral HIV-KS with no Candida growth showed equally low CD4 counts as the 13 oral HIV-KS secondarily infected with Candida; 9 cases had CD4 counts of $<100$ cells $/ \mathrm{mm}^{3}$.

\section{DISCUSSION}

HIV/AIDS has reached epidemic proportions in South Africa, with a dramatic increase in KS frequency. ${ }^{2-4}$ In $21 \%$ of HIV-positive people with $\mathrm{KS}$, the initial presentation is in the mouth, while in $71.5 \%$ the mouth is affected at some time during the course of the disease. The number of oral $\mathrm{KS}$ cases in the Department of Oral Pathology increased from 84 cases over a 29-year period (1973-2002) to 133 new cases during the five-year study period (2003-2007). ${ }^{5}$ There has however been a $70-80 \%$ reduction in the risk of developing KS in South Africa, where up to $48 \%$ of HIVinfected adults are positive for HHV8. ${ }^{6}$

This study showed a secondary Candida infection rate of oral HIV-KS of only $40.6 \%$. Many histopathologists anecdotally believe that the secondary Candida infection rate of HIV-KS is much higher. There are no comparable studies of infection rate or histomorphology of Candida secondary infection of oral HIV-KS to which the results of this study can be compared.

When considering reasons for the relatively low infection rate, it must be realised that the surface epithelium covering oral KS or oral HIV-KS may be unique and not comparable with other HIV-related lesions or even with normal epithelium in an HIV-positive patient. Oral HIV-KS may well influence the surface epithelium by induction from cytokines, prostaglandins and genetic influences, all of which influence the oral epithelial response to $C$. albicans penetration. ${ }^{7,8}$ Oral HIV-KS cells may create a unique micro-milieu not reproducible in other situations. 


\begin{tabular}{|c|c|}
\hline $\begin{array}{l}\text { CD4 T cell count } \\
\text { (cells } / \mathrm{mm}^{3} \text { ) }\end{array}$ & Histological Features \\
\hline $599-500$ & $\begin{array}{l}\text { - Candida pseudohyphae and yeast cells in } \\
\text { epithelium in all cases } \\
\text { - multiple loci of infection } \\
\text { - mild acute and/or chronic infection in all cases } \\
\text { - mild epithelial hyperplasia }\end{array}$ \\
\hline $499-400$ & No correlating data available for this subset \\
\hline $399-300$ & No correlating data available for this subset \\
\hline $299-200$ & $\begin{array}{l}\text { - Candida pseudohyphae and yeast cells in } \\
\text { epithelium in all cases } \\
\text { - multiple loci of infection } \\
\text { - mild acute and/or chronic infection in all cases } \\
\text { - a single case of severe infection } \\
\text { - moderate epithelial hyperplasia }\end{array}$ \\
\hline $199-100$ & No correlating data available for this subset \\
\hline $99-0$ & $\begin{array}{l}\text { - Candida pseudohyphae and yeast cells in } \\
\text { epithelium in all cases } \\
\text { - } 2 \text { cases with Candida invasion into spinous } \\
\text { epithelial layer } \\
\text { - multiple loci of infection, } \\
\text { - mild acute and/or chronic infection in all cases } \\
\text { - a single case each of moderate and severe } \\
\text { infection } \\
\text { - moderate epithelial hyperplasia }\end{array}$ \\
\hline
\end{tabular}

One cannot infer that mechanisms by which secondary Candida infection of oral HIV-KS occur are the same as those of primary Candida penetration in HIV-positive and HIV-negative patients or in other situations of oral Candida infection, and more importantly in other mucosal sites. For example, whilst oropharyngeal candidiasis occurs commonly in HIV-positive women Candida infection is rarely seen in vaginal mucosa of the same cohort. ${ }^{7}$

Oral Candida infection rates in HIV-positive patients vary from $26.3 \%$ (India) $^{9}$ and $38 \%$ (Tanzania) to 94\% (Zaire), and range from $37.8 \%$ to $63 \%$ in South Africa. ${ }^{10}$ Our findings of secondary Candida infection rate in oral HIV-KS (40.6\%) are consistent with previous reports.

In South Africa, though KS was regarded as occurring predominantly in males, greater female involvement is recorded. ${ }^{2}$ The KS incidence has doubled in men and increased 7 -fold in women resulting in a M:F ratio decline from 7:1 (1988) to 2:1 (2001). ${ }^{2}$ A previous study in our Department showed M:F ratio of 1.3:1 in 81 oral HIV-KS during 1997-2003. ${ }^{5}$ This was suggested to be due to differences in mode of HIV transmission, which is predominantly heterosexual in South Africa. ${ }^{5}$ The current study showed a prominent female predominance in oral HIV-KS, consistent with the dramatic increase in HIV infection of women in this population. ${ }^{11}$ In Africa across all ages, more females than males are infected with HIV, which may explain the M:F ratio reversal in favour of females. This gender imbalance of HIV-infected persons in Africa is most marked amongst the 15-24 age group, where M:F ratio is 1:4.11 The decrease in M:F ratio of HIV$\mathrm{KS}$ in Africa due to ART is unlikely as the decline occurred before ART availability and HIV-KS incidence has not changed significantly since ART introduction. ${ }^{11}$

HIV-KS is reported in all ages; mainly in the third and fourth decades of life. ${ }^{5}$ Our study reported a predominance in third and fourth decades with no difference in age between HIV-KS patients secondarily infected with Candida and those who were not. Oral KS most frequently affects the palate, gingiva and dorsum of tongue. ${ }^{5}$ Our study demonstrated a similar predilection of oral HIV-KS for the palate followed by the tongue in HIV-positive patients regardless of secondary Candida infection.

Oral HIV-KS may develop at any stage of HIV infection and especially when CD4 T-cell counts fall below 200 cells/mm.12 Our study confirmed that most oral HIV-KS occurred at CD4 counts $<100$ cells $/ \mathrm{mm}^{3}$. There was no difference in CD4 counts between lesions infected and those not secondarily infected with C. albicans. This implies that CD4 cells are not a determining factor in the pathogenesis of secondary candidiasis in oral HIV-KS. This remains to be confirmed with a larger study sample. A similar study showed $75 \%$ of $130 \mathrm{HIV}-\mathrm{KS}$ had CD4 counts of $<200$ cells $/ \mathrm{mm} 3$ confirming that low CD4 counts are not a prerequisite for HIV-KS development. ${ }^{13}$ Previous reports show that CD4 T-cell numbers are markedly reduced in the oral mucosa of HIV-positive patients with or without candidiasis, and that $C$. albicans specific peripheral CD4 T-cells are depleted with HIV disease progression and concurrent oral candidiasis. ${ }^{14}$

This study is the first to establish the frequency of secondary Candida infection in oral HIV-KS and to describe the histomorphology. Candida pseudohyphae were present in epithelium overlying oral HIV-KS. Severity of Candida infection varied from single isolated pseudohyphae to matted colonies of fungal organisms. Morphology of less severe Candida infections closely mimicked that of immune competent hosts whereas severe Candida infections in oral HIV-KS showed more numerous and deeper penetration of Candida organisms than that in immune competent hosts.

Our study confirmed that Candida infection regardless of severity, rarely reaches the lamina propria by penetration through epithelium. In the single case where the organism penetrated connective tissue and $\mathrm{KS}$ tissue, it entered through the necrotic ulcerated surface, and not through intact epithelium. The reasons for this are unclear but perhaps the more anaerobic conditions found deep in the epithelium limit the depth of infiltration by organisms.

Further, Candida is epitheliotrophic and depends on attachment and penetrative biological processes to infect host tissue. ${ }^{7}$ It is uncertain whether these characteristics are inherent in either or both the organism and the host epithelium. Invasion of pyogenic membrane shows that epithelial factors are not absolutely essential for organism growth but that under exceptional circumstances organisms are capable of living in the fibrinopurulent exudate.

\section{CONCLUSION}

Only less than half of the cases of oral HIV-KS were secondarily infected with Candida. This may be due to the fact that many oral HIV-KS are covered by a pyogenic membrane. Furthermore, Candida is strongly epitheliotrophic and Candida infection in the fibrinopurulent 
exudate overlying oral HIV-KS is unusual. The relatively low frequency of secondary Candida infection of oral HIV$\mathrm{KS}$, its deep tissue penetration, and its presence in the absence of inflammation requires further investigation.

\section{Acknowledgements}

The authors thank Ms Amina Kaskar for her excellent technical assistance.

\section{References}

1. Williams DW, Jordan RP, Wei XQ, et al. Interactions of Candida albicans with host epithelial surfaces. J Oral Microbiol. 2013; 5; doi:10.3402/jom.v5i0.22434.

2. Sitas F, Newton R. Kaposi's sarcoma in South Africa. J Natl Cancer Inst Monogr. 2001; 28: 1-4.

3. Rees CA, Keating EM, Lukolyo $\mathrm{H}$, et al. Mapping the epidemiology of Kaposi sarcoma and Non-Hodgkin lymphoma among children in Sub-Saharan Africa: a review. Pediatr Blood Cancer 2016; 63(8): 1325-31.

4. Meer S, Altini M. Cytomegalovirus co-infection in AIDSassociated oral Kaposi's sarcoma. Adv Dent Res. 2006; 19(1): 96-8.

5. Lager I, Altini M, Coleman H, Ali H. Oral Kaposi's sarcoma: a clinicopathologic study from South Africa. Oral Surg Oral Med Oral Pathol Oral Radiol Endod. 2003; 96(6): 701-10.

6. Bohlius J, Valeri F, Maskew M, et al. Kaposi's sarcoma in HIV-infected patients in South Africa: multicohort study in the antiretroviral therapy era. Int J Cancer 2014; 135(11): 2644-52.

7. De Repentigny L, Lewandowski D, Jolicoeur P. Immunopathogenesis of oropharyngeal candidiasis in human immunodeficiency virus infection. Clin Microbiol Rev. 2004; 17(4): 729-59.

8. Jivan V, Meer S. Quantification of oral palatine Langerhans cells in HIV/AIDS associated oral Kaposi sarcoma with and without oral candidiasis. J Cancer Res Ther. 2016; 12(2): 705-11.

9. SanadhyaYK, Sanadhya S, Nagarajappa R, Jain $S$, Aapaliya P, Sharma N. Correlation between oral lesions and opportunistic infections among human immunodeficiency virus-infected individuals in Indian population. Int Marit Health 2014; 65(3): 124-30.

10. Naidoo S, Chikte U. HIV/AIDS - the evolving pandemic and its impact on oral health in sub-Saharan Africa. SADJ. 1999;:.54(12): 616-30.

11. UN Joint Programme on HIV/AIDS (UNAIDS). Global AIDS Update - 2016, http://www.refworld.org/docid/574e8d394. html [accessed 24 September 2017]

12. Wojcicki JM, Newton R, Urban Ml, et al. Risk factors for high anti-HHV-8 antibody titres (> or $=1: 51,200$ ) in black, HIV-1 negative South African cancer patients: a case control study. BMC Infect Dis. 2003; 3: 21-5.

13. Jung AC, Paauw DS. Diagnosing HIV-related disease : using the CD4 count as a guide. J Gen Intern Med. 1998; 13(2): 131-6.

14. Kunkl A, Mortara L, Valle MT, et al. Recognition of antigenic clusters of Candida albicans by T lymphocytes from human immunodeficiency virus-infected persons. J Infect Dis. 1998; 178(2): 488-96. 